\title{
Management of neglected femur neck fractures treated with non vascularised fibular graft
}

\author{
Arun Gopalakrishnan ${ }^{1}$, Sreesobh K.V., ${ }^{2, *}$ Jijo Jose ${ }^{3}$ \\ ${ }^{1}$ Assistant Professor, ${ }^{2}$ Associate Professor, ${ }^{3}$ Assistant Professor, Dept. of Orthopaedics, PK Das Institute of Medical Sciences, \\ Palakkad, Vaniamkulam, Kerala, India
}

*Corresponding Author:

Email: drsreesobh@gmail.com

\begin{abstract}
Intracapsular femoral neck fractures are seen commonly in elderly people following a low energy trauma. 2-3\% of all femoral neck fractures occurs in adults younger than 50 years and is often the result of high-energy trauma. Femoral neck fracture continues to be considered as an unsolved fracture in view of poor prognosis and variable outcome reported after different procedures. In developing countries the fracture often remains untreated as the patients do not seek treatment due to non availability of treatment facility or may be treated primarily by osteopaths or operated under suboptimal theatre conditions with poor quality implants. We prospectively studied the outcome of 54 patients managed with non vascularised fibular graft and cancellous screws between 2010-2015. ANOVA test was used as a test of significance and functional results were assessed by Modified Askin and Bryan criteria. To conclude, in patients younger than 60 years of age with neglected femoral neck fracture, non vascularised fibular graft acts as a reliable biological implant for revascularisation and gives excellent functional outcome.
\end{abstract}

Keywords: Neglected neck, Femur fracture.

\section{Introduction}

Neck of femur fractures are most commonly seen in elderly age group. ${ }^{1}$ Due to increase in high velocity injuries and sports injuries, femoral neck fractures have become more common in younger age group. $2-3 \%$ of all femoral neck fractures occurs in young adults and is often due to high energy trauma. ${ }^{2}$ Fe moral neck fracture has a devastating effect on the blood supply of the femoral head, which is related to the severity of injury and displacement of the fracture. ${ }^{3}$ The intracapsular hematoma is also implicated with development of avascular necrosis of femoral head. Femoral neck fracture in young adults are associated with higher incidence of osteonecrosis, with rate as high as 12$86 \% .^{4}$ As literature says, anatomical reduction and stable fixation restore the vascularity and reduce the chances of AVN. Non union and AVN of femoral head are the main complication after neck of femur fracture. Reasons being precarious vascularity, shearing forces at the fracture site, inadequate reduction and improper fixation. In developing countries, the fracture is often diagnosed late due to shortage of required facilities and availability of alternate options like osteopaths. Apart from this, lack of experienced hands may further deteriorate the outcome. Neck of femur fractures, even in modern era still considered to be an unsolved fracture in view of poor prognosis and unexpected outcome. The aim of this study was to assess the outcomes in terms of fracture union and functional scores, treated with non vascularised fibular graft and cancellous screws.

\section{Materials and Methods}

The protocol of this study was approved by the institutional review board. This study was authorized by the local ethical committee and was performed in accordance with the ethical standards of the 1964 Declaration of Helsinki as revised in 2000. Informed written consent was taken from all the patients.

The inclusion criteria were as follows:

1. Age between 18 years and 60 years

2. At least 3 weeks of delay after fracture

The exclusion criteria were:

1. Infective non-union

2. Associated medical complications for surgery

3. Established avascular necrosis of femur head

4. Pathological fractures.

Before planning for surgery, we classified neglected neck of femur fractures based on Sandhu's classification. Sandhu $\mathrm{u}^{5}$ described a classification system for NU/neglected femoral neck fracture based on radiological findings. He classified the neglected femoral neck fracture into 3 stages

1. Stage I

a. Fracture surfaces are still irregular

b. The size of the proximal frag ment is $2.5 \mathrm{~cm}$ or more

c. Gap between the fragments is $1 \mathrm{~cm}$ or less

d. Head of the femur is viable with no sign of AVN on X-ray or MRI.

2. Stage II

a. Fracture surfaces are smooth and sclerosed.

b. The size of the proximal fragment is $2.5 \mathrm{~cm}$ or more

c. The gap between the fragments is more than $1 \mathrm{~cm}$ but $<2.5 \mathrm{~cm}$

d. The head of the femur is viable.

3. Stage III

a. Fracture surfaces are smoothened out 
b. The size of the proximal fragment is $<2.5 \mathrm{~cm}$

c. The gap between the fragments is more than 2.5 $\mathrm{cm}$

d. The head of the femur shows signs of AVN. The presence of any of the latter three, that is, proximal fragment $<2.5 \mathrm{~cm}$, (inadequate for good hold of implant) or fracture gap more than $2.5 \mathrm{~cm}$ or head of femur has A VN are placed in stage III marks the fracture unsuitable for osteosynthesis.

We included patients who were falling in Sandhu's stage 1 and stage2. (Fig. 1)

We operated all patients in supine position on a fracture table. Closed reduction was done in most of the fractures. Flexion with gentle traction and external rotation was done to disengage the fragments and then slow extension and internal rotation was carried out to achieve reduction. Reduction was confirmed with AP and lateral v iews, based on the Garden alignment index. When closed reduction fails, we did open reduction. We used Watson-Jones anterolateral approach to the hip with exposure of the fracture through an anterior capsular incision. This also allows removal of fibrous tissue between the fragments encouraging revascularisation and absolute compression across the fracture site. After getting good reduction, we proceed to harvest non vascularised free fibular graft. Fibular graft was harvested from the ipsilateral leg using a posterolateral approach. The periosteum over the lateral border of the fibula was cut and an 8-cm long segment of bone was exposed. We removed the entire fibula with the help of saw and osteotome. (Fig. 3) Periosteum was sutured back. Graft ( $8 \mathrm{~cm}$ in length) was taken out and drill holes were made using a $2.5 \mathrm{~mm}$ drill bit at regular intervals $2 \mathrm{~cm}$ apart on its surfaces for better incorporation of the graft. A guide wire passed with the help of C-arm in the centre of neck. Its position was confirmed in both AP and lateral views. With the help of an $8 \mathrm{~mm}$ reamer used for PFN, we reamed over the guide wire. Harvested fibular graft was sized accordingly to the reamed diameter and was put into the neck and hammered. (Fig. 4) With the available space in the neck superiorly and inferiorly to the graft, 2 cannulated cancellous screws were put in the neck. After confirming stability, wound was closed. Patient was put on non weight bearing walking for first 6 weeks. Once the radiological signs of union were seen, patient was asked to do full weight bearing walking without support (Fig. 2). In the follow up, outcome was as sessed by Modified Askin and Bryan criteria. ${ }^{6}$

Modified Askin and Bryan criteria.

Excellent: No pain, near normal gait, $<20 \%$ restriction of ROM, normal activity.

Good: $\quad$ Mild pain \& limp, 20-40\% restriction of ROM, mild restriction of activity.

Fair: Continuous pain, marked restriction of ROM and activity, need walking aid.
Data was entered into Microsoft excel data sheet and was analyzed using SPSS 22 version software. Categorical data was represented in the form of Frequencies and proportions. Continuous data was represented as mean and SD. ANOVA test was used as test of significance to identify the mean difference between four quantitative variables. MS Excel and MS word was used to obtain various types of graphs such as bar diagram and Pie diagram. p value (Probability that the result is true) of $<0.05$ was considered as statistically significant after assuming all the rules of statis tical tests.

Statistical Software: MS Excel, SPSS version 22 (IBM SPSS Statistics, So mers NY, USA) was used to analyze data.

Table 1: Age distribution of subjects in the study

\begin{tabular}{|c|c|c|c|}
\hline \multicolumn{2}{|c|}{} & Count & $\%$ \\
\hline \multirow{4}{*}{ Age } & $<30$ years & 23 & $42.6 \%$ \\
\cline { 2 - 4 } & 31 to 40 years & 14 & $25.9 \%$ \\
\cline { 2 - 4 } & $>40$ years & 17 & $31.5 \%$ \\
\hline
\end{tabular}

\section{Results}

The study included 54 patients of neglected neck of femur fractures operated between 2010-2015 in our hospital. The average age of the patients was 34 years (range 18-60 years).Majority of subjects were in the age group <30 years ( 18 to 30 years) i.e. $42.6 \%$. Out of this, 34 were males and 20 were females. The interval between the injury and the time of surgery ranged from 22 to 153 days (average: 52 days ).Majority of subjects were followed up till 2 to 3 years (44\%), 32\% were followed up for 3 to 4 years, $20 \%$ were followed up for $>4$ years. Mean age of subjects was $34.1 \pm 9.7$ years, mean days of neglect was $52 \pm 26.3$ days, and time to union was $6.6 \pm 1.6$ months and mean duration of follow up $39.2 \pm 9.7$ months. There was positive correlation between Age and Time of Union i.e. with increase in age of the subjects there was increase in Time of Union in subjects and Vice versa. However there was no significant correlation between Age and Time to Union. There was negative correlation between Mean days of Neglect and Time of Union i.e. with increase in Mean days of Neglect among subjects there was increase in Time of Union in subjects and Vice versa. However, there was no significant correlation between Mean days of neglect and Time to Union. In this study, $48.1 \%$ had excellent functional result, $37 \%$ had good functional result and $7.4 \%$ had fair and poor functional results respectively. Mean days of Neglect among those with excellent result was $46.1 \pm 17$ days, among those with good functional outcome was $49.3 \pm$ 19.6 days, among those with fair results was $37.3 \pm$ 13.1 and among those with poor functional result mean days of neglect was $117.8 \pm 28.2$ days. There was significant difference in mean days of neglect between functional outcomes. Mean Time of Union (Months) among those with excellent result was $6.3 \pm 1$ months, 
among those with good functional result was $6.4 \pm 1.6$ months and mean time of union among those with fair functional results was $8.5 \pm 3.1$ months. This difference in mean time to union between functional results was statistically significant i.e. those with higher time of union had fair functional result and vice versa. In our study, 4 patients developed avascular necrosis with secondary osteoarthritis changes that is about $7.4 \%$ for which total hip replacement was done.

\section{Discussion}

Fractures of femoral neck still remain an enig ma in the practice of orthopaedic surgeons. The debate still exists all over the world regarding its management. Generally, there are very few options available to treat neglected non union neck femur fractures. Like osteosynthesis with or without vascularised or nonvascularised fibular grafting, ${ }^{8}$ valgus intertrochanteric osteotomy, ${ }^{7}$ osteosynthesis with muscle pedicle bone grafting ${ }^{9,10}$ and replacement (hemiarthroplasty or Total hip Replacement).

When the fracture neck of the femur is of more than 3 weeks duration, internal fixation alone has a very high failure rate. Internal fixation has to be combined with some type of bone graft or osteotomy particula rly in young patients below the age of 60 years in whom it is desirable to preserve the joint. Osteotomy has been used to alter biomechanics at the fracture site to promote healing. Several types of osteotomy have been described in literature such as medial displacement osteotomy (McMurrays) or angulation osteotomies. However, osteotomy has its as sociated problems such as, shortening, limp, decreased range of movement, increased risk of osteonecrosis and potential risk of non-union. So, non vascularised fibular graft is a better and established option. Fibular graft provides sufficient osteo-conductive and osteo-inductive potential which acts as a reliable biological implant for revascularisation and its trephine shape adds to the rotational stability minimising the need for additional implant.

Stewart and Wells ${ }^{11}$ in a series of 100 patients treated with osteotomy and internal fixation reported high rate of non-union (46\%) including at the osteotomy site.

Lifeso and Young ${ }^{12}$ felt that valgus osteotomy gave acceptable results but concluded that non-union in young adults was difficult to treat they reported nonunion in 3 and osteonecrosis in 2 out of 28 cases.

Jaiswal et $\mathrm{al}^{13}$ showed dual fibular bone grafting for neglected femoral neck fractures is simple and cost effective method with good results.

Fibular osteosynthesis in neglected femoral neck fracture was popularized by Nagi et al. ${ }^{8}$ They used one cancellous screw and a fibular graft in their patients and reported union in all of them. They acknowledge that fibular osteosynthesis not only promotes union, it also improves the osteonecrosis in the femoral head.
Goyal et $\mathrm{al}^{14}$ in a series of 15 patient treated by single fibular graft and two cannulated hip screw reported union in 14 cases. They reported good result in 11 and satisfactory result in 2 patients.

The concept of hip preservation in neglected cases of fracture neck femur is well proved in the literature. But recently, many surgeons are going for arthroplasty in this type of neglected cases. Considering Indian population and their demands, which is usually squatting and sitting cross legged, preservation of the head should be the first option instead of arthroplasty. This procedure is also economically feasible and outcome is better than other alternatives for management of neglected femur neck fracture.

There are few complications and minimal donor site morbidity after autogenous free fibular bone grafting. The coxa vara deformity and leg length discrepancy that have been reported after free fibular grafting is because of preoperative varus alignment or varus malreduction during surgery. Even in varus hip, fibular graft osteosynthesis promotes union. Reported incidence of AVN following neglected femoral neck fractures ranges between $0 \%$ to $67 \%$ with most reports being $<15 \%$. Our study reported $7.4 \%$ of A VN which is comparable with literature. This may be due to closed reduction in most of the cases and anatomical reduction which may have reduced the incidence of $\mathrm{AVN}$ in our series.

This study concludes that mean time to union of neglected neck of femur fractures with non vascularised fibular graft and a cancellous screw was $6.6 \pm 1.6$ months. Lower the time of union, better the functional results i.e. with increase in time of union, functional results were fair and good. Functional outcome depended significantly on mean days of neglect, i.e. with increase in mean days of neglect, functional outcome was poor. As far as our knowledge, no study has reported the association between duration of neglect and functional outcome. This study holds its uniqueness in analysing the relation between days of neglect with fracture union and functional scores. The limitation of this study is small sample size from a single centre hence significant conclusions could not be drawn. Results of this study are comparable with the reported literatures in terms of functional outcome and complication rates.

Table 2: Mean values of various parameters in the study

\begin{tabular}{|l|c|c|}
\hline & Mean & SD \\
\hline Age (Years) & 34.1 & 9.7 \\
\hline Mean days of Neglect & 52.0 & 26.3 \\
\hline Time to Union (Months) & 6.6 & 1.6 \\
\hline Follow up (Months) & 39.2 & 9.7 \\
\hline
\end{tabular}


Table 3: Correlation between age and time of union

\begin{tabular}{|c|c|c|c|}
\hline \multicolumn{2}{|c|}{} & Age & $\begin{array}{c}\text { Time to Union } \\
\text { (Months) }\end{array}$ \\
\hline \multirow{4}{*}{ Age } & $\begin{array}{c}\text { Pearson } \\
\text { Correlation }\end{array}$ & 1 & 0.125 \\
\cline { 2 - 4 } & P value & & 0.387 \\
\cline { 2 - 4 } & $\mathrm{N}$ & 54 & 50 \\
\hline
\end{tabular}

Table 4: Follow up period of subjects in the study

\begin{tabular}{|c|c|c|c|}
\hline \multicolumn{2}{|c|}{} & Count & \% \\
\hline \multirow{4}{*}{ Follow up } & 2 years & 2 & $4.0 \%$ \\
\cline { 2 - 4 } & 2 to 3 years & 22 & $44.0 \%$ \\
\cline { 2 - 4 } & 3 to 4 years & 16 & $32.0 \%$ \\
\cline { 2 - 4 } & $>4$ years & 10 & $20.0 \%$ \\
\hline
\end{tabular}

Table 5: Functional results of subjects at the end of follow up period

\begin{tabular}{|l|c|c|c|}
\hline \multicolumn{2}{|c|}{} & Count & \% \\
\hline \multirow{3}{*}{$\begin{array}{l}\text { Functional } \\
\text { result }\end{array}$} & Excellent & 26 & $48.1 \%$ \\
\cline { 2 - 4 } & Good & 20 & $37.0 \%$ \\
\cline { 2 - 4 } & Fair & 4 & $7.4 \%$ \\
\cline { 2 - 4 } & Poor & 4 & $7.4 \%$ \\
\hline
\end{tabular}

Table 6: Mean days of neglect and time of union comparis on between functional results

\begin{tabular}{|c|c|c|c|c|c|c|c|c|c|}
\hline & \multicolumn{8}{|c|}{ Functional result } & \multirow[t]{3}{*}{$P$ value } \\
\hline & \multicolumn{2}{|c|}{ Excellent } & \multicolumn{2}{|c|}{ Good } & \multicolumn{2}{|c|}{ Fair } & \multicolumn{2}{|c|}{ Poor } & \\
\hline & Mean & $\mathrm{SD}$ & Mean & SD & Mean & SD & Mean & $\mathrm{SD}$ & \\
\hline Mean to Neglect (days) & 46.1 & 17.0 & 49.3 & 19.6 & 37.3 & 13.1 & 117.8 & 28.2 & $<0.001 *$ \\
\hline Time to Union (Months) & 6.3 & 1.0 & 6.4 & 1.6 & 8.5 & 3.1 & . & . & $0.029 *$ \\
\hline
\end{tabular}

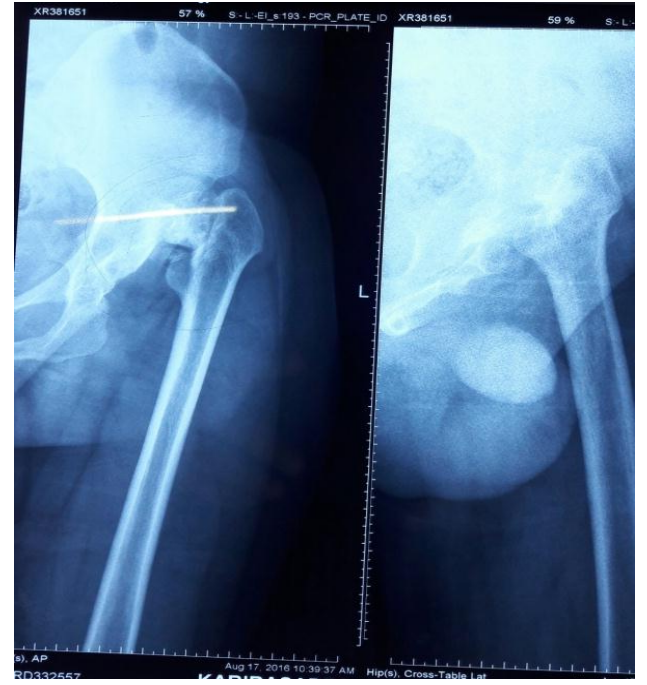

Fig. 1: Showing fracture non union of femur neck left side

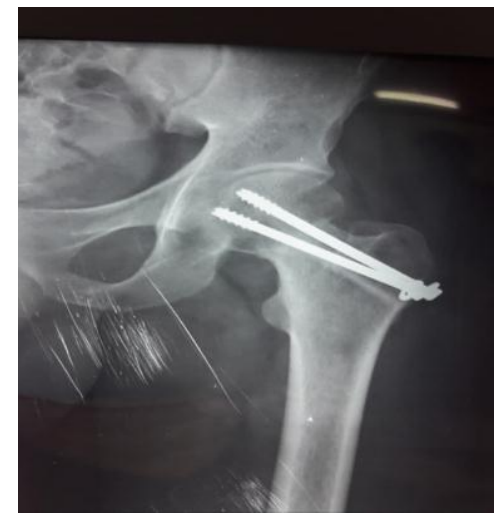

Fig. 2: Showing united fracture with cancellous screw insitu and visible fibular graft
Fig. 3: Showing harvested fibular graft

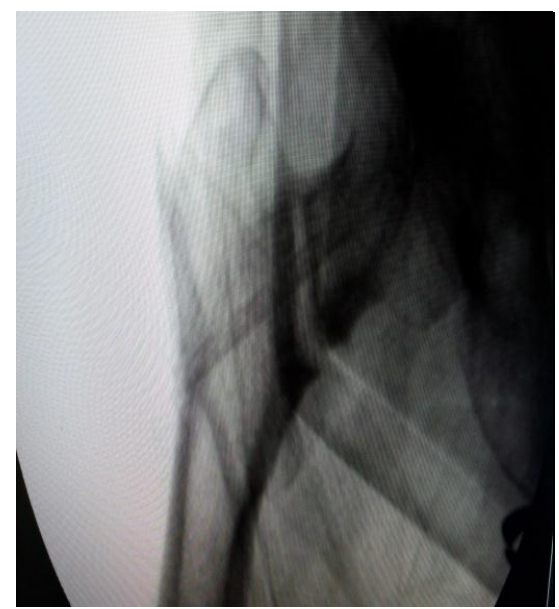

Fig. 4: Showing well positioned graft 


\section{Conclusion}

To conclude, in patients younger than 60 years of age with neglected femoral neck fracture, non vascularised fibular graft acts as a reliable biological implant for revascularisation and gives excellent functional outcome.

\section{References}

1. Karagas MR, Lu-Yao GL, Barrett JA, Beach ML, Baron JA. Heterogeneity of hip fracture: age, race, sex, and geographic patterns of femoral neck and trochanteric fractures among the US elderly. Am J Epidemiol. 1996;143:677-682.

2. Robinson CM, Court-Brown CM, McQueen MM, Christie J. Hip fractures in adults younger than 50 years of age. Epidemiology and results. Clin Orthop Relat Res. 1995;(312):238-246.

3. Protzman R.R., Burkhalter W.C. Femoral neck fractures in young adults. J Bone Joint Surg [Am] 1976;58:689695.

4. Ehlinger M, Moser T, Adam P, Bierry G, Gangi A, de Mathelin M, et al. Early prediction of femoral head avascular necrosis following neck fracture. Orthop Traumatol Surg Res. 2011;97:79-88.

5. Sandhu HS. Management of fracture neck of femur. Indian J Orthop. 2005;39:130-6.

6. Askin S.R., Bryan R.S. Femoral neck fractures in young adults. Clin Orthop. 1976;114:259-264.

7. Mueller M.E. The intertrochanteric osteotomy and pseudarthrosis of the femoral neck. Clin Orthop. 1999;363:5-8.

8. Nagi O.N., Gautam V.K., Marya S.K.S. Treatment of femoral neck fractures with cancellous screws and fibular graft. J Bone Joint Surg [Br] 1986;68:387-391.

9. Baksi D.P. Internal fixation of ununited femoral neck fracture combined with muscle pedicle grafting. J Bone Joint Surg [Br] 1986;68:239-245.

10. Meyers M.H., Moore T.M., Harvey J.P., Jr. Displaced fractures of the femoral neck treated with muscle-pedicle graft: with emphasis on treatment of these fractures in young adults. J Bone Joint Surg [Am] 1974;57:718-720.

11. Stewart MJ, Wells RE. Osteotomy and osteotomy combined with bone-grafting for non-union following fract ure of the femoral neck. J Bone Joint Surg Am 1956;38-A:33-48.

12. Lifeso R, Younge D. The neglected hip fracture. J Orthop Trauma 1990;4:287-292.

13. Jaiswal A, Pruthi KK, Goyal RK, et al. Evaluation of osteosynthesis with dual fibular bone grafting for neglected femoral neck fractures. J Clin Orthop and Trauma 2013;4:58-69.

14. Goyal RK, Chandra H, Pruthi KK, Nirvikalp Fibular grafting with cannulated hip screw fixation in late femoral neck fracture in young adults. Indian J Orthop. 2006;40:94-6. 